\title{
NUMERICAL ANALYSIS OF STRESS INTENSITY FACTOR IN SPECIMENS WITH DIFFERENT FILLET GEOMETRY SUBJECTED TO BENDING
}

\author{
Janusz LEWANDOWSKI*, Dariusz ROZUMEK* \\ ${ }^{*}$ Faculty of Mechanical Engineering, Department of Mechanics and Machine Design, Opole University of Technology, \\ ul. Mikołajczyka 5, 45-271 Opole, Poland \\ janusz210@wp.pl, d.rozumek@po.opole.pl
}

received 5 April 2017, revised 28 February 2018, accepted 5 March 2018

\begin{abstract}
The article presents the maps of $x x$ stress component and compares values of analytical and numerical calculations for the stress intensity factor range of welded specimens with fillet welds which subjected to cyclic bending. The tests were performed under constant value of moment amplitude $M_{a}=9.20 \mathrm{~N} \cdot \mathrm{m}$ and stress ratio $R=\sigma_{\min } / \sigma_{\max }=-1$. The specimens were made of drag steel rod S355. The specimens were solid and welded. The numerical models were simulated with ABAQUS suite and numerical calculations performed with FRANC3D software.
\end{abstract}

Key words: Numerical Method, Fatigue Crack Growth, Bending

\section{INTRODUCTION}

Dynamically increasing competitiveness in quality, economy and consumer expectations force producers to optimize production in the way that products are of top quality and costs are maximally reduced at the same time. The problem of costeffectiveness in production process concerns all industries. Engineering industry has no possibility to conduct research since they are expensive; therefore it cooperates with research institutions/centers (e.g. universities) to verify the structural solutions. In these centers the numerous research are conducted on the specimens with static and dynamic load to answer questions about strength and life. Experimenting with specimens on strength testing machines is expensive and time-consuming. The specimens are only in the simple shapes. Nevertheless, the results of the experiments give knowledge about the behavior of elements, material, welded joints, etc. in the real environment, considering all limitations of the tested element or the material structure (Carpinitieri et al., 2005; Zhi-Gang et al., 2012; Shang et al., 2015; Pakandam and Varvani-Farahani, 2010; Balitskii and Kostyuk, 2009; Rozumek and Marciniak, 2012; Poutiainen and Marquis, 2006; Benachour et al., 2008; Niklas, 2014; Rozumek, 2009). Nowadays, the numerical calculations are commonly performed together with experiments. These calculations provide for the analysis of stress, strain and displacement of the structures which are of different complexity and dimension and working under constant and variable loads (Tanaka et al., 2014; Ferro et al., 2016; Lewandowski and Rozumek, 2016). The crucial point is that numerical calculations do not reflect fully the behavior of the material or structure (Rusiński, 2002; Duchaczek and Mańko, 2012). The reason for this is that many simplifications are introduced into the calculation, such as:: the size of a single finite or boundary element (from which a construction model was made), the adoption of a perfectly isotropic material, the adoption of faulty initial assumptions (points of application and load values, etc.). The numerical calculations performed by people without basic knowledge of the subjects give sometimes completely erroneous results. Therefore, the results of the numerical calculations are often verified by experimental results.

The aim of the paper is to analyze the stress intensity factor and values of experimental (analytical) and numerical calculations for the stress intensity factor range of welded specimens with different fillet geometry subjected to cyclic bending.

\section{SUBJECT OF STUDY}

The analytical and numerical calculations were performed on the basis of three types of specimens made of $\$ 355$ steel i.e., the solid specimen and the of welded specimens with fillet welds (concave and convex). Shapes and dimensions of the specimens are presented in Fig. 1 (solid specimen, specimens with concave and convex welds), and mechanical properties are given in Tab. 1.

Tab. 1. Monotonic mechanical properties of S355 steel

\begin{tabular}{|c|c|c|c|c|}
\hline $\begin{array}{c}\text { Yield stress, } \\
\sigma_{\mathrm{y}}(\mathrm{MPa})\end{array}$ & $\begin{array}{c}\text { Ultimate } \\
\text { stress, } \sigma_{\mathrm{u}} \\
(\mathrm{MPa})\end{array}$ & $\begin{array}{c}\text { Elongation, } \mathrm{A}_{5} \\
(\%)\end{array}$ & $\begin{array}{c}\text { Young's } \\
\text { modulus, } \mathrm{E} \\
(\mathrm{GPa})\end{array}$ & $\begin{array}{c}\text { Poisson's } \\
\text { ratio v }\end{array}$ \\
\hline 357 & 535 & 21 & 210 & 0.30 \\
\hline
\end{tabular}

Hand-made welds were made based on the TIG method using the inert gas shielding (Argon) for protection. The theoretical stress concentration factor in the solid specimen under bending $\mathrm{K}_{\mathrm{t}}$ $=1.38$ was estimated with use of the model (Kocańda and Szala, 1985; Rozumek and Macha, 2009).

Fig. 2 presents the microstructure of the solid specimen 
material and the parent material (for welded specimens) of S355 steel. This material has a fine-grained ferritic-perlitic structure (Lewandowski and Rozumek, 2016).

Chemical composition of the tested S355 steel shown in the Tab. 2.

a)

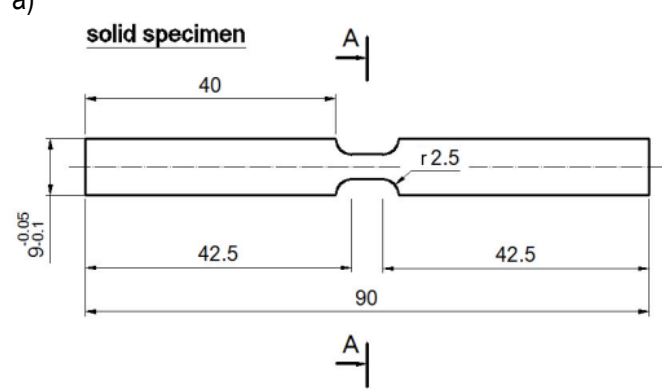

$\underline{A-A}$

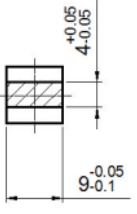

b)

specimen with concave welds

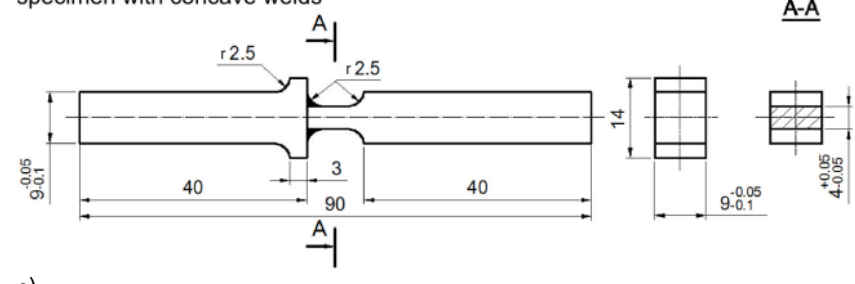

c)

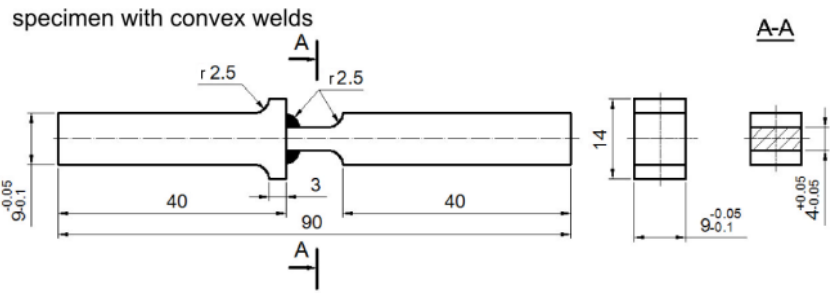

Fig. 1. Shapes and dimensions of specimens: (a) solid specimen, (b) specimen with concave welds, and (c) specimen with convex welds, dimensions in $\mathrm{mm}$

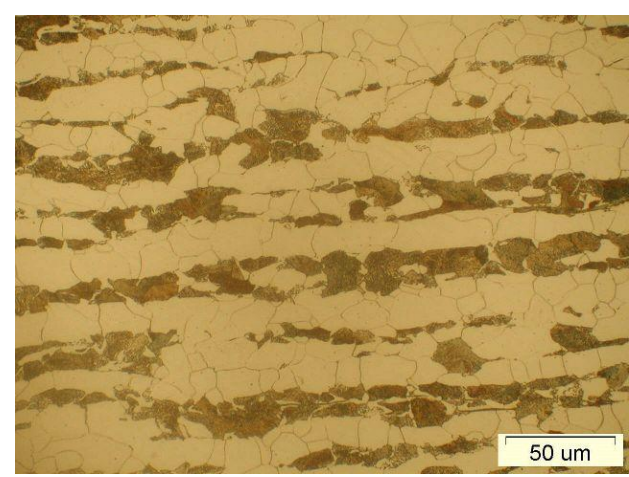

Fig. 2. The microstructure of the base material (magnification 500x)

Tab. 2. Chemical composition (in wt $\%$ ) of S 355 steel

\begin{tabular}{|c|c|c|c|c|c|c|c|c|}
\hline $\mathrm{C}$ & $\mathrm{Mn}$ & $\mathrm{Si}$ & $\mathrm{P}$ & $\mathrm{S}$ & $\mathrm{Cr}$ & $\mathrm{Ni}$ & $\mathrm{Cu}$ & $\mathrm{Fe}$ \\
\hline 0.2 & 1.49 & 0.33 & 0.023 & 0.024 & 0.01 & 0.01 & 0.035 & Bal. \\
\hline
\end{tabular}

The analytical and numerical calculations were performed for bending specimens at constant value of moment amplitude $\mathrm{M}_{\mathrm{a}}$ $=9.20 \mathrm{~N} \cdot \mathrm{m}$. The tests was carried out at loading frequency 28.4 $\mathrm{Hz}$ and stress ratio $\mathrm{R}=-1$. Fig. 3 presents the method how the specimens were fixed and loaded.

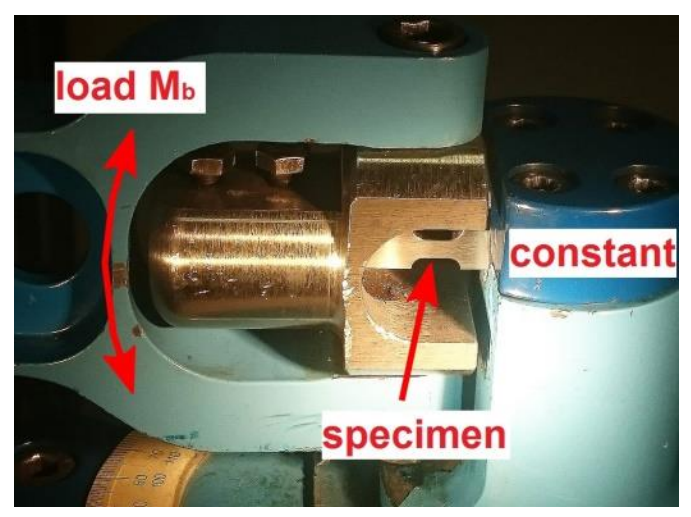

Fig. 3. Method of restrained and specimens loaded

\section{NUMERICAL COMPUTATIONS}

\subsection{Description of the software for numerical computations}

The numerical models were simulated with ABAQUS suite which applies finite element method (FEM). Besides building the model the program allows analysis of stress, strain and displacement and visualization of the results in a form of diagrams or maps. The limitation of ABAQUS is the lack of the tool for simulating cracks or cracks growth. Therefore, the FRANC3D software was chosen for that purpose (Faszynka et al., 2016; www.cfg. cornell.edu/software/software.htm). The program performs calculations based on the boundary element method (BEM). The capabilities of the program allow, among other things, for simulating crack growth by the given value and calculating stress intensity factors. For numerical calculations with ABAQUS program three test samples without cracks were made. These models served as a base for further calculations. The first numerical calculations were performed, which resulted in stress maps ( $\sigma x x$ component of stress tensor) for the analyzed specimens without cracks. Then the files with models were transported to FRANC3D, where the cracks $a=0.10 \mathrm{~mm}$ long on the top surface, on the top of the notch were simulated. These cracks run perpendicular to the length of the specimen. Finite element mesh was made of tetrahedrons. The side length of the single element for solid specimens and for the specimens with concave welds was $0.25 \mathrm{~mm}$, and for specimens with concave welds of $0.37 \mathrm{~mm}$. However, in the stress concentration zones and in the crack growth, the size of the element side was $0.03 \mathrm{~mm}$ (Rusiński, 2002; Faszynka et al., 2016). Fig. 4 presents simulated cracks for the analyzed specimens: solid specimens with concave and convex welds.

After cracks simulation (crack initiation), FRANC3D software calculates the stress intensity factors for the given crack lengths. Next, models with cracks $0.10 \mathrm{~mm}$ long were transferred to ABAQUS to perform numerical calculations to get the stress maps for the analyzed specimens.

At the subsequent stages, repeatedly another cracks growth in length were simulated using FRANC3D and stress intensity factors were calculated as well as the stresses using the ABAQUS were calculated. The important rule applied for the research was that the lengths of cracks calculated numerically related to the lengths of the cracks recorded during the experiments. Fig. 5 presents the example specimens with cracks: the solid specimens with the crack $a=1.70 \mathrm{~mm}$ long, the specimen with concave welds and the crack $a=1.44 \mathrm{~mm}$ long, and the specimen with the convex weld and crack $a=1.48 \mathrm{~mm}$ long. FRANC3D software 
calculates the stress intensity factor according to Eq. (1) taking into account the specimen shapes. In the area of developing cracks, the sizes FE mesh was concentrated to obtain the most accurate calculation. Numerical calculation error when changing the element size did not exceed $5 \%$.

b)

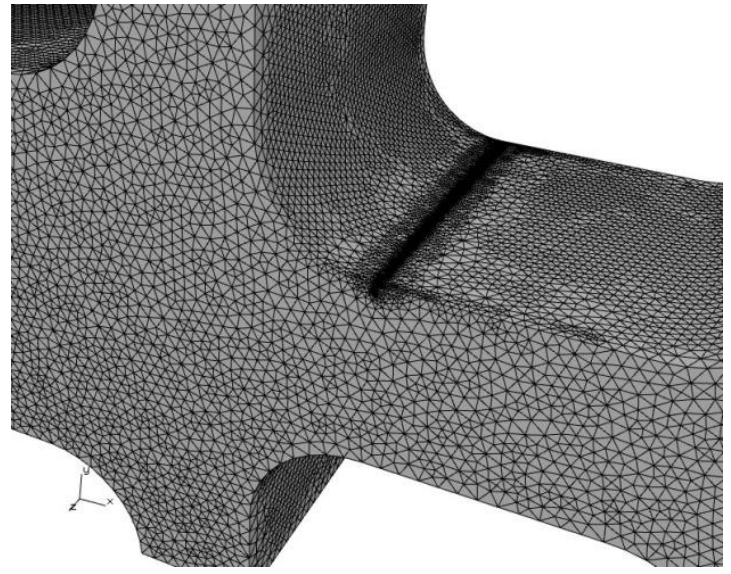

c)

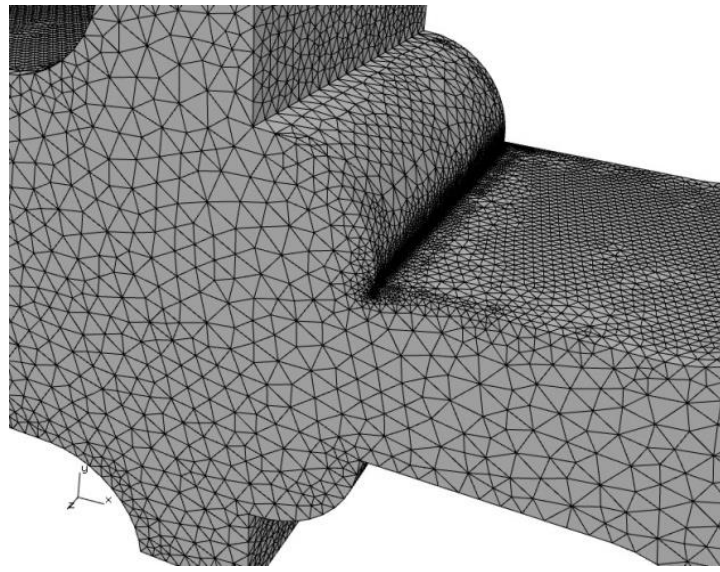

Fig. 4. Crack initiation ( $a=0.10 \mathrm{~mm}$ ) of specimens: a) solid, $b$ ) with concave welds, and c) with convex welds

a)

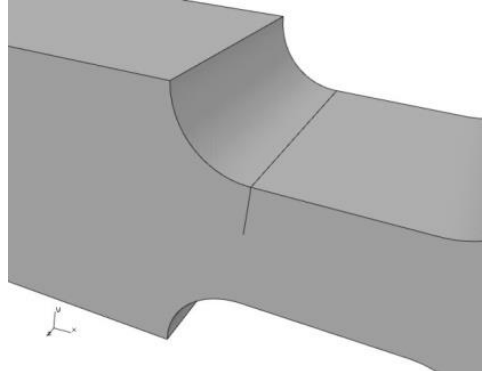

b)

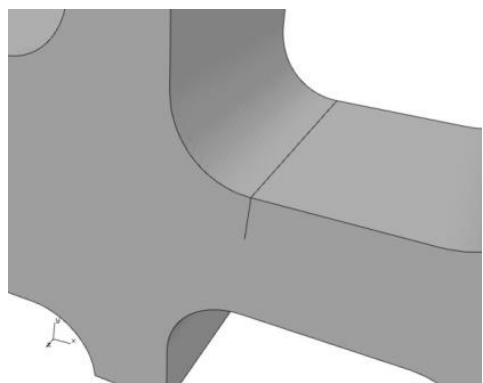

c)

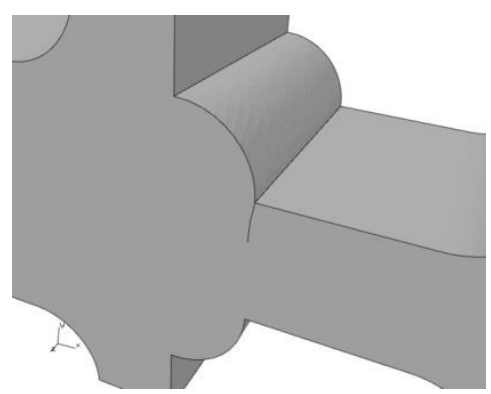

Fig. 5. Specimens with numerical calculation cracks: a) solid, b) with concave welds, and c) with convex welds

\subsection{The results of numerical computations}

The results of the numerical calculations are presented in the forms of stress maps ( $\sigma_{x x}$ component of stress tensor) for three specimen models. Fig. 6 presents specimens without cracks. Fig. 7 presents stresses maps for models with cracks of length: the solid specimen $a=1.70 \mathrm{~mm}$, the specimen with concave welds $a=1.44 \mathrm{~mm}$ and the specimen with the convex weld $\mathrm{a}=1.48 \mathrm{~mm}$.

The subsequent cracks growth was calculated numerically. The values of lengths related to the lengths and directions the cracks run, which were reported during the experiments. Cracks in the specimens tested experimentally run evenly in the cross section of the specimens. The cracks growth in a similar way in the specimens calculated numerically. The values of stresses calculated numerically relate to the values reported during the experiment, which proves that the applied calculation method was correct. Fig. 8 presents results of calculations numerically for the stress intensity factors range.

In numerical calculations, a uniform structure of material is assumed. The differences in properties occurring in the heat affected zone were not taken into account. 
a)

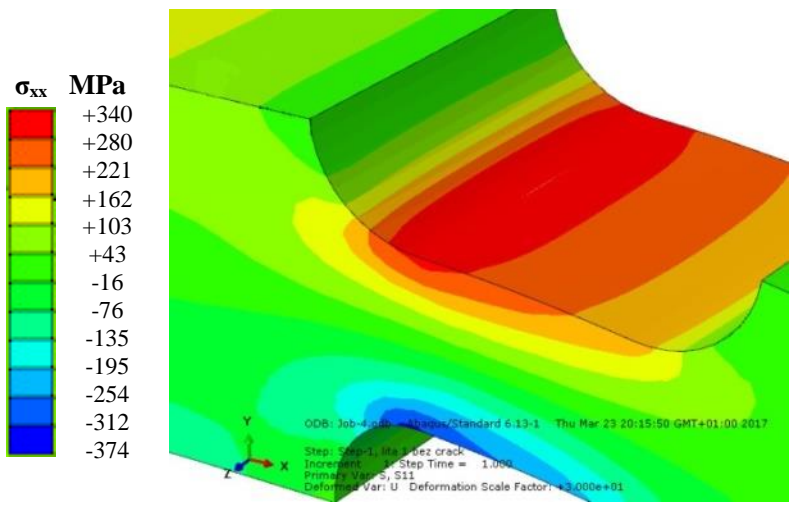

b)

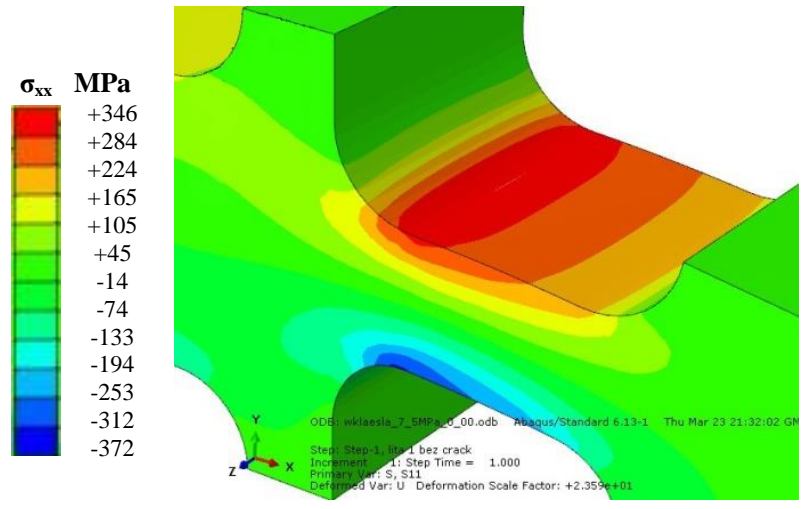

c)

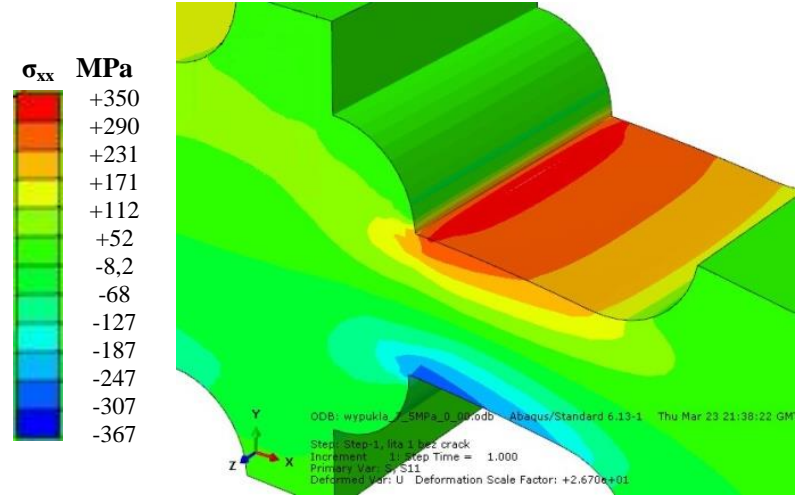

Fig. 6. Distribution of stresses ( $\sigma_{x x}$ component of stress tensor) in models without cracks: a) solid, b) with concave welds, c) with convex welds

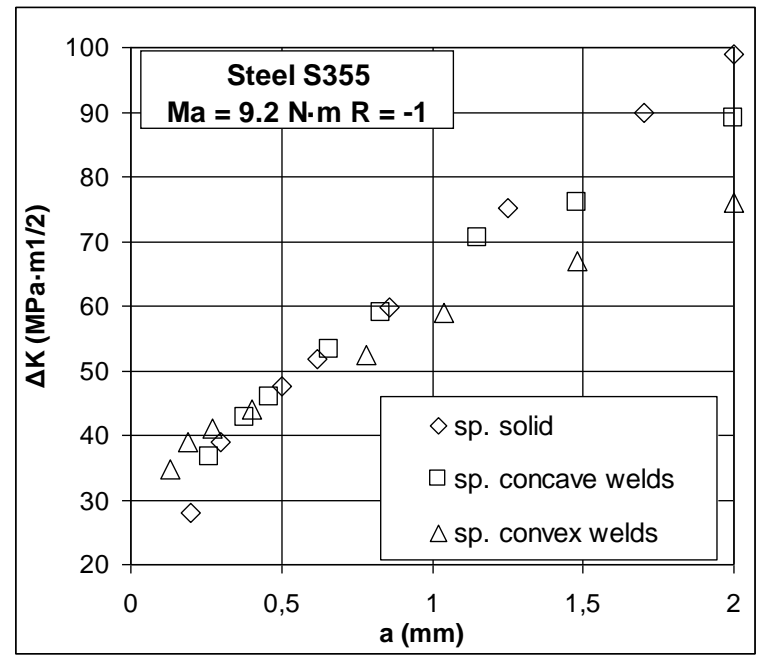

Fig. 8. Stress intensity factor range vs. cracks length calculated numerically a)

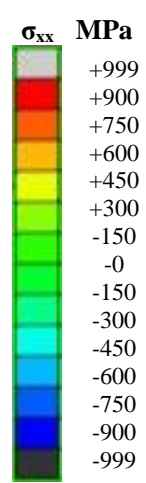

b)

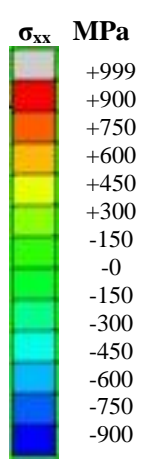

c)
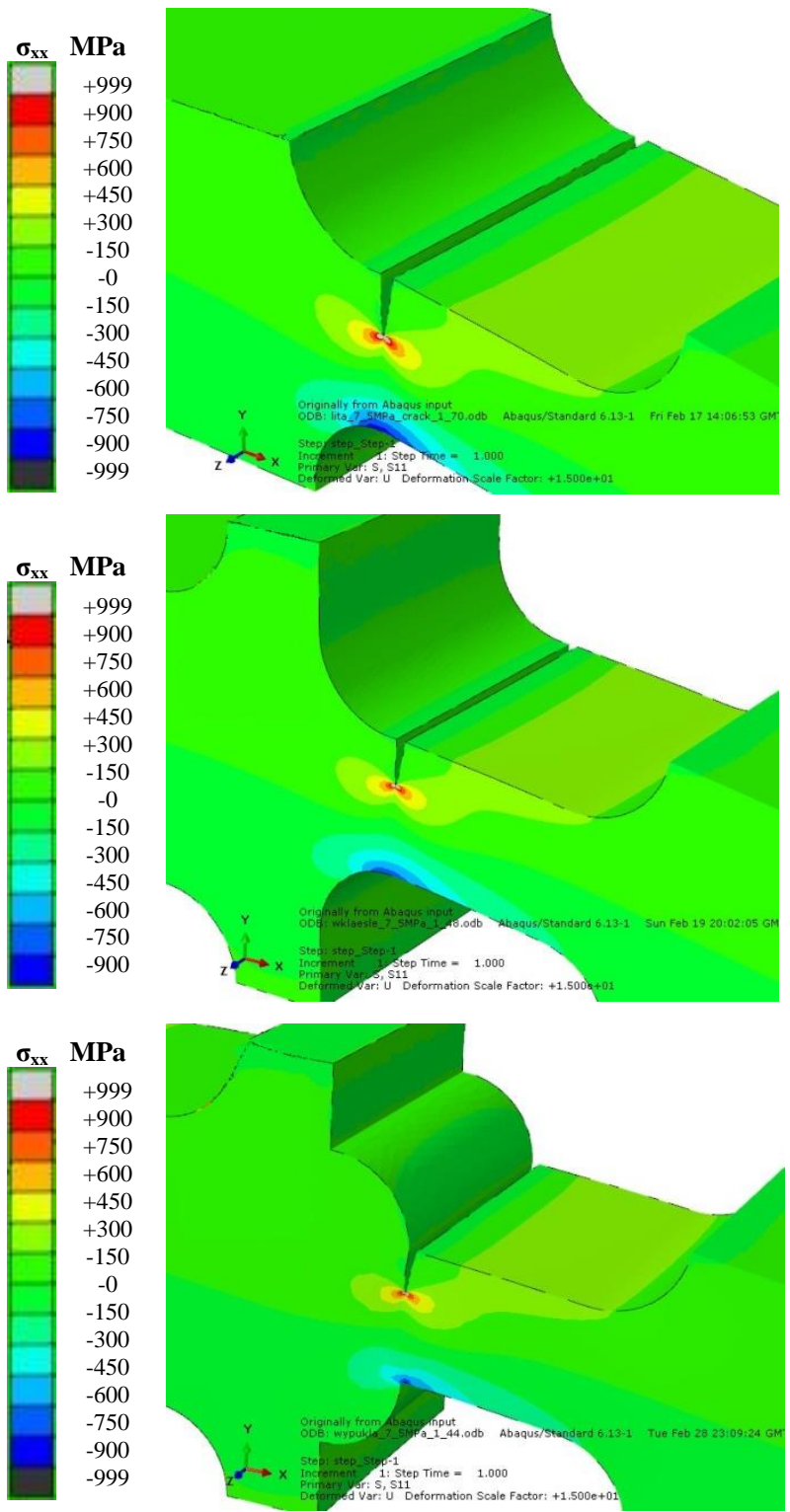

Fig. 7. Distribution of stresses ( $\sigma_{x x}$ component of stress tensor) in models with cracks length: a) solid $a=1.70 \mathrm{~mm}, b$ ) with concave welds $\mathrm{a}=1.44 \mathrm{~mm}, \mathrm{c}$ ) with convex welds $\mathrm{a}=1.48 \mathrm{~mm}$

\section{ANALITYCAL CALCULATIONS}

\subsection{Methodology of conducting computations}

Analytical calculations concentrated mainly on the values of stress intensity factor (SIF and its ranges) for the tested specimens with growing crack. Using the Eq. (1), the stress intensity factors were calculated for the individual crack lengths.

$\Delta K=M_{k} \cdot Y \cdot \Delta \sigma \cdot \sqrt{\pi a}$

where: $\Delta \sigma$ - stress range, $\mathrm{MPa}, a$ - crack length, $\mathrm{mm}, \mathrm{M}_{\mathrm{k}}$ - magnification function taking into account of the welded structure.

The specimen was subjected to bending, so the stresses deciding about demage of the specimen are derived from the stress tensor $\sigma_{x x}$. For the calculation in Eq. (1), $\Delta \sigma=\sigma_{\max }$ (according to the literature (Kocańda and Szala, 1985)) was taken, i.e. in our case $\Delta \sigma=\sigma_{x x}$. 
In order to explain the size of $w$ and $h$ of the weld and designations for equations (1) - (5), added Fig. 9.

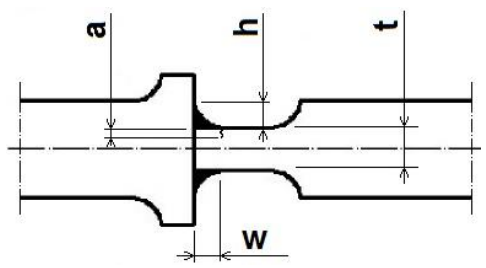

Fig. 9. Size of $w$ and $h$ of the weld and designations for equations (1) - (5)

Correction function $\mathrm{Y}$ for $\Delta \mathrm{K}$ including shape and load of specimens was obtained from the Eq. (Rozumek and Macha, 2009)

$Y=5 / \sqrt{20-13(a / t)-7(a / t)^{2}}$

To calculate stress intensity factor and its ranges for welded specimens the additional correction function were applied. This function included structure and shape of welds in the analyzed specimens. The function $M_{k}$ including the structure of the welded joints is identified (for this specimen) by using the equation $(3,4$, and 5) (Hobbacher, 2008):

$M_{k}=B \cdot\left(\frac{a}{t}\right)^{k}$

where: a - crack length, $\mathrm{mm}, \mathrm{t}$ - specimen thickness, $\mathrm{mm}$.

$B=0.8068-0.1554\left(\frac{h}{t}\right)+0.0429\left(\frac{h}{t}\right)^{2}+0.0794\left(\frac{w}{t}\right)$

where: $\mathrm{h}$ - weld height, $\mathrm{mm}, \mathrm{w}$ - weld width, $\mathrm{mm} \mathrm{t}$ - specimen thickness, $\mathrm{mm}$.

$k=-0.1993-0.1839\left(\frac{h}{t}\right)+0.0495\left(\frac{h}{t}\right)^{2}+0.0815\left(\frac{w}{t}\right)$

\subsection{Results of analytical calculations}

Analytical calculations provided values for stress intensity factor range $\Delta \mathrm{K}$ for solid, concave and convex welds specimens. The results are presented in Fig. 10.

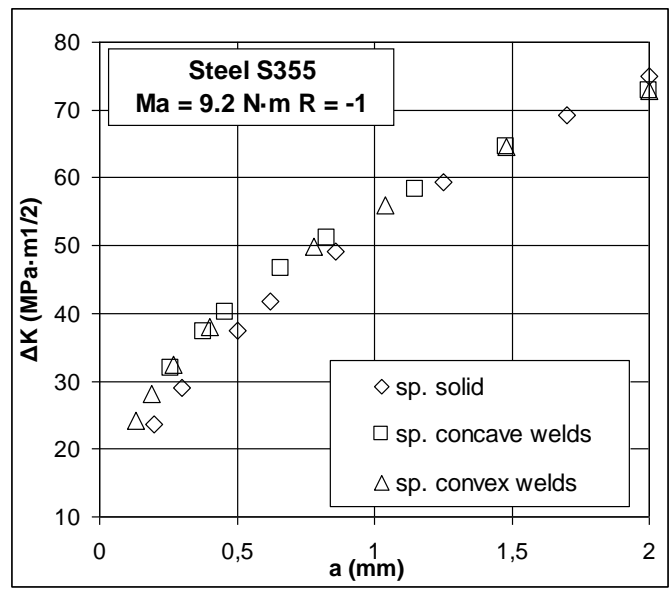

Fig. 10. Stress intensity factor range calculated analytically

\section{COMPARISON OF NUMERICAL CALCULATION WITH ANALYTICAL}

Figs. 11-13 presents the comparison of values for the stress intensity factor ranges $\Delta \mathrm{K}$ obtained independently (numerically and analytically). Fig. 11 presents comparative results for solid specimens, Fig. 12 - the results for specimens with concave welds and Fig.13 - the results for specimens with convex welds.

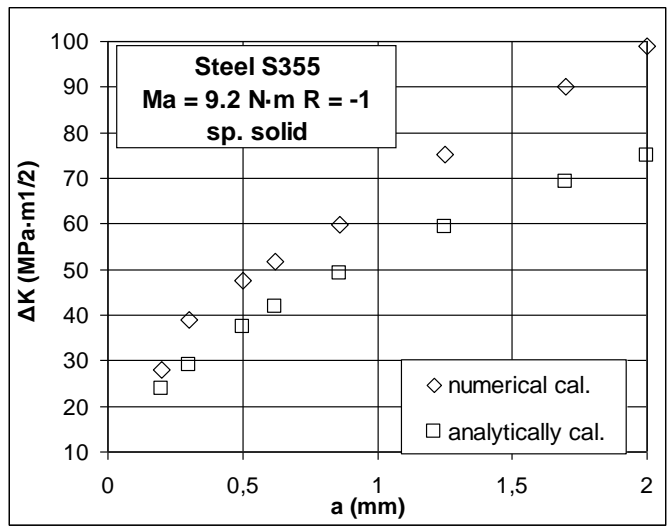

Fig. 11. Comparison of the values stress intensity factor range in crack length function calculated analytically and numerically for solid specimens

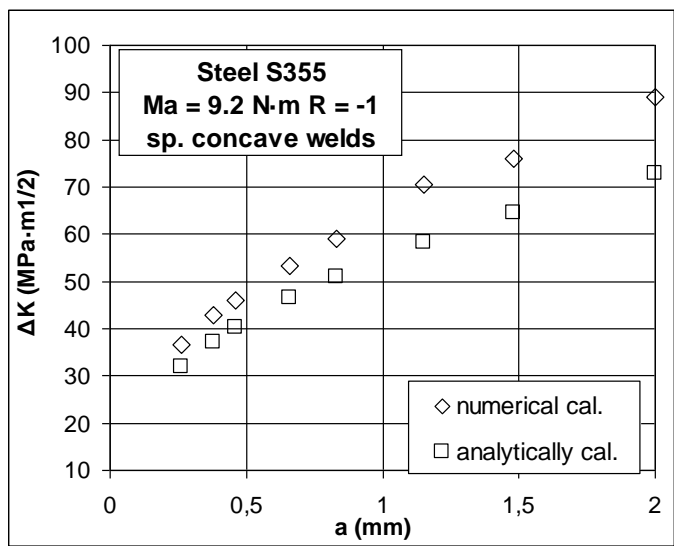

Fig. 12. Comparison of the values stress intensity factor range in crack length function calculated analytically and numerically for concave welds

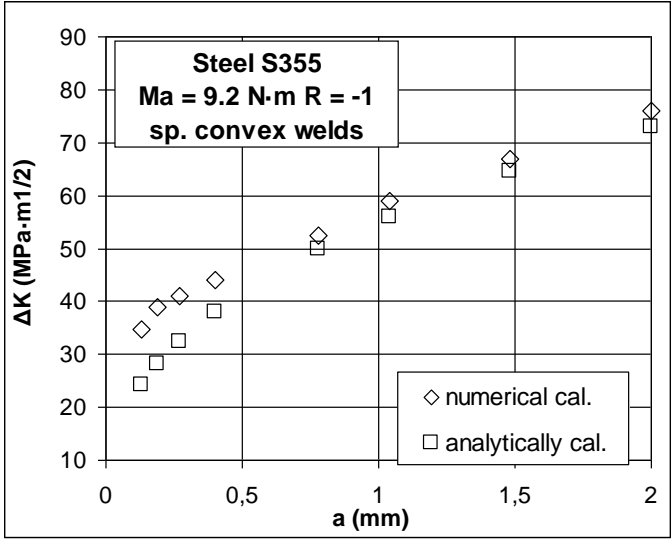

Fig. 13. Comparison of the values stress intensity factor range in crack length function calculated analytically and numerically for convex welds 
The graphs show that the results are similar for the initial crack lengths. For the crack lengths of maximum $1 \mathrm{~mm}$, the differences in values for solid specimens did not exceed $15 \%$, for specimens with concave welds $-13 \%$ and for specimens with convex welds $-5 \%$. Whereas for the crack lengths up to $1.2 \mathrm{~mm}$ the differences in values for solid specimens did not exceed $19 \%$, for specimens with concave welds - $17 \%$ and for specimens with convex welds $-5.5 \%$. For the bigger crack lengths the values are more diverging. It may be concluded then, that with the applied calculation method the results obtained numerically and analytically are similar within a certain range, in that case up to $a=1.2$ $\mathrm{mm}$. For more conformity of the results the calculation method should be modified by including certain correction coefficients. Based on Figs. 11 to 13 we can observe a slightly higher values of $\Delta K$ for numerical calculations. The authors believe that both methods can be applied without significant errors. Numerical calculations should be based on previous experimental studies to ensure the reliability of the results obtained. Numerical SIF calculation takes into account geometrical differences of specimens, because the dependences $\Delta \mathrm{K}$-a are different (Figs. 11-13). Thus, numerical method is more properly for SIF calculation of different geometry specimens.

\section{CONCLUSIONS}

On the basis of obtained results of numerical and analytical calculations the following conclusions can be formulated:

1. Correctly built numerical models provide good results which are similar to results obtained in experiments or analytical calculations.

2. The applied analytical formulas gave similar results to those obtained from numerical calculations for the crack lengths up to $1 \mathrm{~mm}$.

3. The best compatibility of the results was obtained for welded specimens with convex welds. The error for the crack lengths up to $1.2 \mathrm{~mm}$ did not exceed $5.5 \%$.

4. The biggest differences between results are for the solid samples. The error for the crack lengths up to $1.2 \mathrm{~mm}$ did not exceed $19 \%$.

5. The authors paper believe that both methods can be applied without significant errors. In the case of numerical calculations should be based on previous experimental studies to ensure the reliability of the results obtained. Numerical SIF calculation takes into account geometrical differences of specimens, because the dependences $\Delta \mathrm{K}-\mathrm{a}$ are different (Figs. 11-13), therefore the authors propose this method.

\section{REFERENCES}

1. Balitskii O.I., Kostyuk I.F. (2009), Strength of welded joints of Cr$\mathrm{Mn}$ steels with elevated content of nitrogen in hydrogen-containing media, Materials Science, 45, 97-107.

2. Benachour M., Benguediab M., Hadjoui A., Hadjoui F., Benachour N. (2008), Fatigue crack growth of a double fillet weld, Computational Materials Science, 44, 489-495.

3. Carpinteri A., Brighenti R., Huth H.J., Vantadori S. (2005) Fatigue growth of a surface crack in a welded T-joint, Int. J. Fatigue, 27, $59-69$.

4. Duchaczek A., Mańko Z. (2012), Assessment of direct method of calculating stress intensity factor, Journal of Science of the gen. Tadeusz Kosciuszko Military Academy of Land Forces, 3 (165), 336-346 (in Polish).

5. Faszynka S., Lewandowski J., Rozumek D. (2016), Numerical analysis of stress and strain in specimens with rectangular crosssection subjected to torsion and bending with torsion, Acta Mechanica et Automatica, 10, 5-11.

6. Ferro P., Berto F., James M.N. (2016), Asymptotic residual stresses in butt-welded joints under fatigue loading, Theoretical and Applied Fracture Mechanics, 83, 114-124.

7. Hobbacher A. (2008), Recommendations for fatigue design of welded joints and components, International Institute of Welding, doc. XIII-2151r4-07/XV-1254r4-07,Paris, France.

8. Kocańda S., Szala J., (1985), Basics of fatigue calculations, PWN, Warsaw (in Polish).

9. Lewandowski J., Rozumek D. (2016), Cracks growth in S355 steel under cyclic bending with fillet welded joint, Theoretical and Applied Fracture Mechanics, 86, 342-350.

10. Niklas K. (2014), Calculations of notch stress factor of a thin-walled spreader bracket fillet weld with the use of a local stress approach, Engineering Failure Analysis, 45, 326-338.

11. Pakandam F., Varvani-Farahani A. (2010), A comparative study on fatigue damage assessment of welded joints under uniaxial loading based on energy methods, Procedia Engineering, 2, 2027-2035.

12. Poutiainen I., Marquis G.(2006), A fatigue assessment method based on weld stress, International Journal of Fatigue, 28, $1037-1046$.

13. Rozumek D. (2009), Influence of the slot inclination angle in FeP04 steel on fatigue crack growth under tension, Materials \& Design, 30 1859-1865.

14. Rozumek D., Macha E. (2009), J-integral in the description of fatigue crack growth rate induced by different ratios of torsion to bending loading in AlCu4Mg1, Mat.-wiss. u. Werkstofftech., 40 (10), 743-749.

15. Rozumek D., Marciniak Z. (2012), Fatigue properties of notched specimens made of FeP04 steel, Materials Science, 47, 462-469.

16. Rusiński E. (2002), Principles of designing load-bearing structures of automobile vehicles, Wroclaw University of Science and Technology, Wrockaw (in Polish).

17. Shang Y., Shi H., Wang Z., Zhang G. (2015), In-situ SEM study of short fatigue crack propagation behavior in a dissimilar metal welded joint of nuclear power plant, Materials \& Design, 88, 598-609.

18. Tanaka S., Kawahara T., Okada H. (2014), Study on crack propagation simulation of surface crack in welded joint structure, Marine Structures, 39, 315-334.

19. www.cfg.cornell.edu/software/software.htm.

20. Zhi-Gang X., Tao C., Xiao-Ling Z. (2012), Fatigue strength evaluation of transverse fillet welded joints subjected to bending loads, Int. J. Fatigue, 38, 57-64. 